\title{
Os físicos e a medicina da alma no Orto do Esposo
}

\section{Marisa das Neves Henriques}

\section{(2) OpenEdition \\ Journals}

Edição electrónica

URL: http://journals.openedition.org/medievalista/275

DOI: 10.4000/medievalista.275

ISSN: 1646-740X

\section{Editora}

Instituto de Estudos Medievais - FCSH-UNL

\section{Refêrencia eletrónica}

Marisa das Neves Henriques, "Os físicos e a medicina da alma no Orto do Esposo ", Medievalista [Online], 15 | 2014, posto online no dia 01 janeiro 2014, consultado no dia 03 maio 2019. URL : http:// journals.openedition.org/medievalista/275 ; DOI : 10.4000/medievalista.275

(C) IEM 
Título: Os físicos e a medicina da alma no Orto do Esposo

Autor: Marisa das Neves Henriques

Universidade: Coimbra

Faculdade e Departamento / Unidade de Investigação: Secção de Filosofia do

Departamento de Filosofia, Comunicação e Informação da Faculdade de Letras de

Coimbra

Código Postal: 3004-530 COIMBRA

Cidade: Coimbra

País: Portugal

Email: marisaneves.henriques@gmail.com

Fonte: Medievalista [Em linha]. №15, (Janeiro - Junho 2014). Dir. José Mattoso. Lisboa: IEM.

Disponível em: http://www2.fcsh.unl.pt/iem/medievalista/

ISSN: 1646-740X

Data recepção do artigo: 24 de Março de 2013

Data aceitação do artigo: 7 de Novembro de 2013 


\section{Resumo}

No Orto do Esposo, obra de espiritualidade monástica de finais do século XIV ou do início do século $\mathrm{XV}$, é possível notar a presença de alguns físicos, todos eles com um estatuto especial, que decorre da estreita relação entre sagrado e profano.

Mas, mais do que cuidar do corpo, importa interceder pela alma enferma. A saúde reside na salvação, por isso não há ciência secular que possa dedicar-se a tão nobre designio. Daí que Cristo, caelestis medicus, e a Bíblia sejam os protagonistas de uma medicina da alma que a obra prescreve com minúcia, revelando afinidades com os In Cantica de Bernardo de Claraval. É no seio deste modelo monástico que se encontrarão as receitas para promover a terapia da alma e o seu resgate post mortem.

Palavras-chave: Bernardo de Claraval, corpo, físicos, medicina da alma, Orto do Esposo.

\section{Abstract}

In Orto do Esposo, a book from the end of the $\mathrm{XIV}^{\text {th }}$ century or from the beginning of the $\mathrm{XV}^{\text {th }}$ century, that explores monastic spirituality, one can find several physicians, all of them having a special role, in part due to the close relation between the spheres of profane and sacred.

Nevertheless, the priority is taking care of the ill soul, instead of worrying too much about body. Health is synoym of salvation, so there is no secular science that could stand such noble project.

Christ, the caelestis medicus, and the holy Bible, are the protagonists of a soul's medicine that Orto do Esposo prescribes in detail. In these matter, the portuguese text reflects the lesson of St. Bernard's sermons on the Canticle of Canticles. Through the respect to the monastic model, it will be possible to find recipes to promote soul therapy and restauratio post mortem.

Keywords: Bernard of Clairvaux, body, physicians, soul's medicine, Orto do Esposo. 


\title{
Os físicos e a medicina da alma no Orto do Esposo
}

\author{
Marisa das Neves Henriques
}

Apesar de todas as suas virtudes, aquele prodigioso físico do capítulo I do Livro III do Orto do Esposo ${ }^{1}$ não teria suspeitado vir a renascer pelo punho imaginativo de Jorge de Sena no século XX. Na categoria actancial em que surge, no interior da obra medieva de anónimo autor, ele é o mais notável, porque, ao derramar o seu sangue virgem, ${ }^{2}$ salva a vida a uma nobre dama e ao seu exército, constituído por 500 cavaleiros. Por sete vezes será imersa a senhora do castelo no casto líquido que correra nas veias do príncipe, recuperando nesse banho a sua quẽẽtura natural. ${ }^{3}$ Depois de varios físicos terem tentado, em vão, curá-la é o pródigo viandante que traz o revigoramento à castelã e ressuscita os soldados mortos. Dom de excecionalidade à parte (que três prebendas fortalecem), o jovem físico não é o único a assomar ao longo dos quatro Livros da obra quatrocentista com capacidade de dirimir afeções e de inverter o curso da morte, como veremos.

No Prólogo da obra, o autor acredita que a leitura do OE pode revelar-se proveitosa para um público abrangente que contempla, entre outros, alguns filhos da vulnerabilidade. Relembremos o passo:

\footnotetext{
${ }^{1}$ Citaremos a partir de Orto do Esposo. Ed. de Bertil Maler. Rio de Janeiro: Ministério da Educação e Cultura, 1956, p. 58. (Doravante OE).

${ }^{2}$ Sobre a relação do derramamento de sangue presente neste exemplum com a matéria da Bretanha, vd. Margarida MADUREIRA - "Sangue Redentor: o Orto do Esposo, a Queste del Saint Graal e a tradição exemplar medieval". In Leonor Curado NEVES et alii (coords.) - Matéria da Bretanha em Portugal. Lisboa: Edições Colibri, 2002, p. 241-249.

${ }^{3}$ OE, Livro III, cap. I, p. 38.
} 
“... asy em este liuro som conteudas mujtas cousas pera mãtimẽto e deleitaçom e meezinha e cõsolaçõ das almas (...) ca em este liuro achara (...) o tybo cõ que sse accenda e o fraco con que se conforte e o o ẽfermo cõ que seia sãão e o sãão cõ que seia guardado em sua saude e o cansado cõ que seia recriado...". ${ }^{4}$

Conforto moral e restabelecimento corporal parecem dimanar de uma medicina da alma que a lectio divina integra e aprofunda, pois "as palavras de Deus (...) som leytoayro e meezinha pera saude e consolaçom da alma". ${ }^{5}$

Pela leitura integral do escrito ascético português, constata-se que os físicos ${ }^{6}$ surgem no interior dos exempla, ora como praticantes da ciência médica, ora assumindo papéis mais sui generis - confirmando atos de fé $e^{7}$ e lutando contra forças demoníacas ${ }^{8}$ que se apossam dos corpos. Esta última faceta aproxima tais personagens da tradição dos antigos magi, familiarizados com o sobrenatural e com a presciência, dimensões que Thorndike harmoniza na sua obra de referência sobre o assunto. ${ }^{9}$ A relação entre a ciência e a religião atesta-se, por exemplo, na recriação do desafio que Dinis lança a $S$. Paulo de curar um cego, não sem uma advertência preliminar: "Mais nõ huses de palauras magicas, qua per uẽtura sabes tu taaes palauras que am este poderio." ${ }^{10} \mathrm{Na}$ senda desta contaminação de funções, também comparecem na obra, um "escollar nigromateco" ${ }^{\prime 1}$ e um encantador. ${ }^{12}$

\footnotetext{
${ }^{4}$ OE, Livro I, Prólogo, p. 2.

${ }^{5}$ OE, Livro III, cap. III, p. 44.

${ }^{6}$ Eis a sucinta definição de física, apresentada no OE, no Livro IV, cap. XLIV, p. 254: "a fisica faz aos homẽẽs que a ham, fisicos...". Sobre a longevidade do uso do nome físico para designar aquele que pratica a arte de curar, vd. Germano de SOUSA - História da Medicina portuguesa durante a Expansão. Lisboa: Temas e Debates, 2013, p. 59. O físico preparava os medicamentos para curar os seus doentes, mas, por vezes, também vendia as drogas que podiam ser usadas em várias artes mecânicas. Vd., sobre a especialização das profissões relacionadas com a medicina, Charles-Henri FIALON - "Histoire des mots «pharmacien» et «apothicaire»". In Bulletin de la Société d'histoire de la pharmacie. Vol. 8, 1920, p. $262-269$.

${ }^{7}$ É o caso do físico do Livro I, cap. II, p. 8, que explica a morte de um homem místico nos seguintes termos: "Certamẽte cõ o grande prazer foy partido per meo seo coraçõ."

${ }^{8}$ OE, Livro IV, cap. LXI, p. 318.

${ }^{9}$ Lynn THOMDIKE - A history of magic and experimental science. New York: Columbia University Press, 1953-1959, 8 vols. Vd. ainda Plinio PRIORESCHI - A History of Medicine: Medieval Medicine. Omaha: Horatius Press, 2003, cap. II, especialmente p. 26 e segs.

${ }^{10}$ OE, Livro I, cap. I, p. 7.

${ }^{11}$ OE, Livro I, cap. V, p. 12.
} 
Apesar de tudo, a physica mantém-se na ala das ciências seculares, cuidando daquilo que menos interessa (aparentemente) à medicina da alma. A esta importa a dissipação da "pestelença do peccado" 13 e a restauratio post mortem, pelo que o sofrimento da carne, encarado com naturalidade, faz parte do trajeto de libertação salvífica. Não admira, por isso, que o vocabulário usado para descrever as doenças físicas seja aplicado na análise das afeções da alma, ${ }^{14}$ que vive em permanente luta contra o visco mundanal. Escusado será também dizer que neste artigo fazemos um uso provocatório da expressão medicina da alma, na medida em que ela radica em correntes da filosofia antiga, cuja influência o cristianismo nem sempre reconhece, mas que são prova das afinidades entre saber clássico e religião cristã. Basta para isso ler as reflexões de Volke sobre o epicurismo, ${ }^{15}$ que mostram a tendência para colocar, lado a lado, "le philosophe et le médecin", "l'ignorance du non-philosophe et la maladie", "apprentissage de la philosophie" / "guérison". 16

Naquele que é um acrisolado convite à renúncia do corpo e das suas seduções, o papel do físico é disputado por outros agentes, tais como os simples e puros de coração, que não são apenas os eleitos do Senhor, como concentram qualidades para se salvaren a si mesmos, ${ }^{17}$ e os santos. ${ }^{18}$ Porém, o supremo "buticayro e hũguentayro"19 é Deus, cujo nome tem propriedades medicinais exímias. Na verdade, estabelecendo uma grande afinidade com os In Cantica de S. Bernardo, os capítulos dos Livro I do OE enfatizam o

\footnotetext{
${ }^{12}$ OE, Livro I, cap. V, p. 13.

${ }^{13}$ OE, Livro I, cap. III, p. 9. Na verdade, dar saúde é sinónimo de derrotar o inimigo que põe em risco a alma (p. 11), preservando-a do fogo do pecado (p. 13).

${ }^{14}$ Mencione-se um dos vocábulos mais marcantes (compunctio) que Dom Jeam Leclercq assinala em L'amour des Lettres et le Désir de Dieu. 4" éd, Paris: Cerf, 2008, p. 34-35: "le mot compunctio [...] désigne les élancements d'une douleur aiguë, d'un mal physique. Mais il a surtout été employé dans le vocabulaire chrétien avec un sens qui, sans perdre contact avec ses origines, est cependant plus riche et beaucoup plus éléve. La componction devient une douleur de l'âme, une douleur qui a, simultanément, deux principes : d'une part le fait du péché et de notre tendance au péché...".

${ }^{15}$ André-Jean VOELKE - La philosophie comme thérapie de l'âme. Paris : Cerf, 1993, especialmente o cap. 3 - «Santé de l'âme et bonheur de la raison», p. 35-57.

${ }^{16}$ André-Jean VOELKE - op. cit., p. xv.

${ }^{17}$ Pense-se, por exemplo, no homem que escreveu o nomen Dei na água e que, de seguida, a ingeriu, vencendo a febre. Cf. OE, Livro I, cap. III, p. 9.

${ }^{18}$ É o caso de São Círiaco que devolve a saúde à filha de Diocleciano, possuída pelo demónio (OE, Livro I, cap. I, p. 5) ou do poder curativo do solo que alberga os túmulos de Gamaliel, Nicodemos, St. Estêvão e Abibas. Dele exala um perfume mírifico que cura "satenta homẽẽs de desuayradas ẽfirmidades." (OE, Livro II, cap. V, p. 23) Registe-se ainda o caso do eremita que foi assassinado e deitado a um rio, cujas águas passaram então a ter o dom de curar os gafos. (OE, Livro IV, Cap. L, p. 282).

${ }^{19}$ OE, Livro II, cap. II, p. 39.
} 
poder balsâmico e reparador do nome de Deus, sinónimo de saúde, "mãyar e meezinha" ${ }^{20}$ contra "todalas effirmidades e chagas da alma e do corpo". ${ }^{21}$ E que chaga vem a ser esta senão a do pecado original, que a falta de fé e a entrega às tentações minam?

No seu Comentário ao Cântico dos Cânticos, Bernardo de Claraval fala do "caelestis medicus", ${ }^{22}$ e, pela repetição da laudatória frase Oleum effusum nomem tuum, reflete sobre as propriedades curativas dos sagrados unguentos, ${ }^{23}$ anunciando ainda que

\begin{abstract}
"Unus idemque cibus et aegrotis est medicina, et aegratativis dieta; porro et débiles confortat, et delectat valentes. Unus idemque cibus et languorem sanatm et servat sanitatem, et corpus nutrit, et palato sapit." 24
\end{abstract}

Achaques, desânimos e dúvidas, de índole anímica e moral, encontram no Senhor a indefectível fonte de cura e lenitivo. Reparação para os sentidos cansados ${ }^{25}$ e mezinha que resgata a alma do "laço da morte", ${ }^{26}$ o nome de Jesus é vaso medicinal que encerra o testemunho de Lucas 7, 21 (E na mesma hora curou muitos de enfermidades, e males, e espíritos maus, e deu vista a muitos cegos). Daí que salvação e saúde sejam as

\footnotetext{
${ }^{20}$ São semelhantes os termos em que S. Bernardo escreve sobre esta temática. Vejamos a partir de In Cantica, O. C.. Ed. dos monges cistercienses de Espanha. Madrid: BAC, 1987, vol. V, Sermo XV, III. 5, p. 224: "Est procul dubio inter oleum et nomen Sponsi similitudo [...] in triplici quadam qualitate olei, quod lucet, pascit, et ungit ... Fovet ignem, nutrit carnem, lenit dolorem : lux cibus, medicina." ${ }^{21}$ OE, Livro I, cap. I, p. 5.

${ }^{22}$ S. BERNARDO - In Cantica, op. cit., Sermo III, I, 2, p. 100: "Caelestis medicus celerrime subvenit, quia velociter currit sermo eius. Numquid non potio est sermo Dei? Est utique, fortis et vehemens, et scrutans corda et renes " Vd. ainda S. BERNARDO - op. cit., Sermo XXX, III, 7, p. 460 e Sermo XXXI, II, p. 466. Sobre a identificação de Cristo com o médico, é incontornável a tradição literária augustinista. Vd., sobre este assunto, R. ARBESMANN - "The Concept of 'Christus medicus' in St. Augustinus". In Traditio 10 (1954), p. 1-28; É possível encontrar mais referências bibliográficas em Allan D. FITAZGERALD et alii (eds.) - Augustine Through the Ages: An Encyclopedia. USA: Eerdmans Publishing Co, 1999, no verbete health, sickness, da autoria de Donald BURT, p. 419; e em Karl-Heinz LEVEN (ed.) - Antike Medizin. Ein Lexicon. München: Verlag C.H. Beck, 2005, p.128.

${ }^{23}$ S. BERNARDO - In Cantica, op. cit., Sermo XII, I, 1: "Primum siquidem pungitivum sentitur, quia movet ad compunctionem amara recordatio peccatorum, et dolorem facit, cum sequens mitigatorium sit, divinae bonitatis intuitu consolationem dante et sedante dolorem. "

${ }^{24}$ S. BERNARDO - In Cantica, op. cit., Sermo XIV, IV, 6, p. 216.

${ }^{25}$ OE, Livro I, cap. II, p. 7.

${ }^{26}$ OE, Livro I, cap. III, p. 8
} 
promessas apresentadas em uníssono para coroar o bom cristão, sarando todas as feridas que o aguilhão terreno lhe pode infligir.

É ainda São Bernardo que nos ilumina quanto à impossibilidade de o físico medir forças com o caelestis medicus: "Haec omnia mihi sonat, cum insonuerint Iesus. Sumo itaque mihi exempla de homine, et auxilium a potente: illa tamquam pigmentarias species, hoc tamquam unde acuam eas; et facio confectionem, cui similem medicorum nemo facere possit."27

Por conseguinte, na fidelidade a esta tradição exegética revela-se igualmente discreta a comparência dos físicos no $\mathrm{OE}$. Na obra de espiritualidade monástica portuguesa o bem-estar do corpo é de somenos importância, já para não mencionar (em contexto extra-verbal) certa animosidade histórica da Igreja com uma ciência que passará a ser monopolizada por braço laico $^{28}$ e a transpor os hortos medicinais dos mosteiros. Os homens ligados à arte de curar que aqui surgem parecem, assim, migrar de catenae e de compilações de exempla onde superstição e pseudociência, bem e mal andam de mãos dadas.

Bem diferentes dos expedientes dos físicos são os recursos usados pelo Senhor no socorro dos penitentes. ${ }^{29}$ No horto místico não podem faltar as "especias aromaticas", ${ }^{30}$ a partir das quais se fazem santos remédios. São as "heruas virtuosas do orto da Sancta Scriptura" que ajudam a dispor contra as "ẽfirmidades spirituaes"31 e os frutos da cultura monástica que prescreve um modus vivendi beato, com lugar para o "prazer spiritual". ${ }^{32}$ É exatamente neste filão que se encaixa uma possível identificação entre

\footnotetext{
${ }^{27}$ S. BERNARDO - In Cantica, op. cit., Sermo XV, IV, p. 228.

${ }^{28}$ Vd., a este propósito, Eugène-Humbert GUITARD - "Le physicien, et ce qu'en a dit vers 1200 le moine Guiot de Provins: contribution à l'histoire des mœurs et du langage". In Revue d'histoire de la pharmacie, t. 48,1960, p. 319.

${ }^{29}$ S. BERNARDO - In Cantica, op. cit., Sermo XVI, 13, p. 246: "Et quoniam multa erant infirmitates, multa quoque providus medicus medicamina curavit afferre. Atullit spiritum scientiae et pietatis, et spiritum timoris Domini."

${ }^{30}$ OE, Livro II, cap. IV, p. 19: “o encenço da deuaçom e a myrra da mortificaçom da carne e o cinamomõ da renẽbrança da morte e o balsamo da perseverança. Todas estas especias acha o homẽ ẽno orto da Sancta Escriptura e todalas outras especias de uirtudes que som pera saude e meezinha e cõforto das almas...".

${ }^{31}$ OE, Livro II, cap. IX, p. 28.

${ }^{32}$ OE, Livro II, cap. VIII, p. 27. Legítimo e desejável em sede de amor místico, a este deleite divino contrapõe-se o "prazer fingidiço", "conprido de uerdadeyras doores, que os chagam [aos pecadores] muy fortemẽte ẽnos corpos e emnas almas." (OE, Livro IV, cap. XIV, p. 139.) Sobre o prazer alcançado
} 
algumas correntes da filosofia antiga e a medicina da alma cristã, aspeto supracitado. Verifica-se, por exemplo, alguma harmonia entre estóicos, epicuristas e autores cristãos quanto à necessidade de fugir aos bens efémeros para evitar perturbações da alma. Transversal ainda é a proclamação do domínio do espírito sobre o corpo, ${ }^{33}$ que deve ser dominado com "panos vis". 34

Ossatura digna, porque simbólica, só existe mesmo uma - a da ecclesia que acolhe todos os fiéis. Contudo, também ela sucumbe à enfermidade se a Igreja militante for negligente. A imagem apresentada num dos exempla do OE fala por si. ${ }^{35}$

As almas corrompidas e relaxadas colocam em perigo a integridade da morada cristã. Todavia, embora existam maus serviçais, a misericórdia de Deus é infinita e as suas palavras atuam como remédios eficazes para quem revelar vontade em obter a salvação. Assim, no OE, não se prescinde dos conselhos de leitura da Sacra pagina, ${ }^{36}$ cuja ruminatio integra um processo de purificação interior e de conhecimento: "este liuro deue homẽ tomar da mão de Jhesu Christo, rogando-o muy humildosamente e recebẽdoo cõ grande deseyo e mastigãdo-o cõ grande sabor e corporãdo-o ẽna sua alma". ${ }^{37}$ Numa leitura complementar, verifica-se que nos sermões do Abade de Claraval é benquista a intercessão da sabedoria na convalescença dos enfermos:

através da vida contemplativa, por via filosófica, vd. Alain LERNOULD - "Le plaisir dans le néoplatonisme". In Laurence BOULÈGUE e Carlos LEVY (éds.) - Hédonismes. Penser et dire le plaisir dans l'Antiquité et à la Renaissance. Villeneuve d'Ascq: Septentrion Presses Universitaires, 2007, p. 119137.

${ }^{33}$ Vd., por exemplo, SÉNECA - Cartas a Lucílio. Trad. de Segurado e Campos. Lisboa: Fund. Calouste Gulbenkian, 2009, Carta 65, p. 235: "Eu sou algo mais, eu nasci para algo mais do que para ser escravo do meu corpo, a quem não tenho em maior conta que a uma cadeia em torno à minha liberdade. (...) Se algo em mim pode sofrer ataques é o corpo; mas neste desconfortável domicílio habita um espírito livre. (...) O desprezo pelo próprio corpo é a certeza da liberdade."

${ }^{34}$ OE, Livro IV, cap. XIII, p. 135.

${ }^{35}$ OE, Livro I, cap. III, p. 18.

${ }^{36}$ Sobre o poder retemperador da Sacra pagina, vd. OE, Livro III, cap. XII, p. 69.

${ }^{37}$ OE, Livro III, cap. XV, p. 77. 
“15. O Sapientia! Quanta arte medendi in vino et oleo animae meae sanitatem restauras, fortiter suavis et suaviter fortis! Fortis pro me, et suavis mihi. Denique attingis a fine usque ad finem fortiter er disponis omnia suaviter, propellens inimicum et infirmum fovens. Sana me Domine et sanabor ...."38

A par de Deus, também os apóstolos são "nostri medici"39, ao passo que se desvaloriza a opinião médica de outras figuras credenciadas na época (e ao longo de vários séculos), verdadeiras auctoritates na literatura especializada:

\begin{abstract}
"Num Hippocratis seu Galieni sententiam, aut certe de schola, Epsicuri, debui proponere vobis? Christi sum discipulus, Christi discipulus loquor: ego si peregrinum dogma induxero, ipse peccavi. Epicurs atque Hippocra, corporis alter voluptatem, alter bonam habitudinem praefert; meus Magister utriusque rei contemptum praedicat. Animae in corpore vitam quam summo studio iste unde sustentet, ille unde et delectet, inquirit atque inquirere docet,Salvator monet et perdere." 40
\end{abstract}

Menosprezar a materialidade e a aparência em favor da entrega despojada a Deus, numa conquista de valores eternos que ultrapassam a vaidade, a beleza e o cuidado com o carneum animae ergastulum são regras basilares para a elevação espiritual. ${ }^{41} \mathrm{~A}$ alma sã dá saúde ao corpo, mas o contrário não parece ser verdade. Confrontado com o dilema de salvar a alma ou de sofrer pacientemente, até ao fim dos seus dias, várias maleitas

${ }^{38}$ S. BERNARDO - In Cantica, op. cit., Sermo XVI, 15, p. 246.

39 S. BERNARDO - In Cantica, op. cit., Sermo XXX, V, p. 448.

${ }^{40}$ S. BERNARDO - In Cantica, op. cit., Sermo XXX, V, p. 448. Apesar deste ceticismo, o OE refere-se uma vez ao "fisico Galiano". (OE, Livro IV, cap. LI, p. 319)

${ }^{41}$ Daí que o monge não deva desviar-se do caminho da contemplação para enveredar por questões relacionadas com o bem-estar físico, segundo S. BERNARDO - In Cantica, op. cit., Sermo XXX, 11-12, p. 450: "Qui autem invenit dicit: Super salutem et omnem pulchritudinem dilexi sapientiam. Si super salutem et pulchritudinem quanto magis super voluptatem et turpitudinem? Quid vero prodest temperare a voluptatibus, et investigandis diversitatibus complexionum ciborumque varitatibus exquirendis quotidianam expendere curam? (...) Puta te, quaeso, monachum esse, non medicum, nec de complexione iudicandum, sed de professione" 
corporais, ${ }^{42}$ S. Gregório não tergiversará na hora de escolher o castigo físico, com vista à redenção. A saúde espiritual justifica que se sacrifique o corpo - verdadeiro cárcere da alma -, porque o estado de doença é o que mais se adequa à obtenção da virtude. ${ }^{43}$ Tolhido fisicamente, o homem está menos exposto às armadilhas do demónio, perdendo a vontade de se divertir ${ }^{44}$ e de correr atrás de bens transitórios. $\mathrm{O}$ exemplo mais à mão encontra-se em St. Petronilha, ${ }^{45}$ que o pai deixava jazer enferma, a fim de garantir a incorruptibilidade do seu amor a Deus.

Desta feita, também os mártires suportam corajosamente a dor durante os atos de flagelação a que são sujeitos, ${ }^{46}$ encarando a desfiguração como um passo libertador para alcançar a cidade celeste, sob um manto de leveza. Não deixa de ser impressiva a proclamação do Papa Inocêncio V no leito da morte, num misto de desencanto e de pessimismo antropológico:

"E ora vede hu som as rodas do curso da minha vida, hu he a nobreza da minha geeraçom, hu he a ciencia, hu sõ as riquezas que me nõ ualerõ agora, e hu he a fremusura do meu corpo!

E, dizendo esto, discobrio-se ẽnos peitos e pareceo a todos tam mesquinho e tam cõsumido que parecia Lazaro ressuscitado do moymẽto, per que mostraua que a fremusura dos corpos deue seer desprezada como cousa fugidia e que dura muy pouco. ${ }^{, 47}$

Na mesma linha, Alexandre Magno, ao sofrer uma arremetida dos inimigos que lhe provocou uma ferida muito dolorosa, diz com ironia: "Todos me dizẽ que eu som filho

\footnotetext{
${ }^{42}$ OE, Livro III, cap. V, p. 47: "em todo tẽpo da sua vida senpre padeceo ou door de febres ou gota ou door muy forte de estamago...". Um testemunho em primeira pessoa pode ser colhido em S. GREGÓRIO MAGNO - Epistolae. XI, 30. [MIGNE - PL, Registri Epistolarum, vol. 77]

${ }^{43}$ OE, Livro IV, cap. XXIV, p. 177: "Outrossy claramẽte se demostra que a saude corporal he mayor mezquindade [que aenfirmydade] do corpo, ca a emfirmidade corporal lyura o homẽ de muytos males de pena e de culpa, e segue-sse desto que o liura da pena do jnferno. Ca o homẽ sãão do corpo muytas uezes se trabalha pera buscar requezas e delectaçõões corporaes...".

${ }^{44}$ OE, Livro IV, cap. XXIV, p. 176-177: “Outrossy, o homẽ quando he sãão ẽno corpo, anda folga[n]do pellos canpos uerdes e pellos montes e pelas serras e per matas, caçando o[s] ceruo[s] e os gamos e as outras bestas feras e as aves. Mas o ẽfermo do corpo nõ pode esto fazer."

${ }^{45}$ OE, Livro IV, cap. XXIV, p. 180.

${ }^{46}$ Veja-se, por exemplo, o caso de St. Inácio (OE, Livro I, cap. III, p. 9-10).

${ }^{47}$ OE, Livro IV, cap. XVII, p. 148.
} 
de Jupiter, deus do ceeo, mas esta chagua braada e diz que eu som homẽ mortal." ${ }^{, 48}$ Conclui-se que tanto o sofrimento como a iminência da morte agudizam a humildade e intensificam a consciência da fragilidade humana, predisposição essencial para o salvífico desfecho. Em coerência com a sensibilidade cristã, na representação de cenas agónicas que antecedem a partida deste mundo são os clérigos que permanecem à cabeceira do moribundo. Às vezes, também assoma o demónio para angariar as almas que se entregam à perdição.

Se para o homem medieval qualquer distúrbio físico radica no pecado, é comum serem os religiosos e os sábios a intercederem pelo paciente. ${ }^{49}$ A prescrição da virtude ${ }^{50}$ e a condenação da luxúria estão no âmago de uma scientia salutaris que a physica não domina, porque o seu objetivo primeiro é mitigar a dor e curar padecimentos que saltem à vista dos olhos sensíveis.

Ao coração do homem de fé, que tem consciência de ser feito de lodo e cinza, ${ }^{51}$ é grata a ideia de supliciar o corpo para recuperar a sua condição de ser à imagem e semelhança de Deus. Não está, porém, entre as funções do físico exercer uma medicina da alma que purifique e reconduza os homens ao seu Criador. Mais próximo desta via medicinal parece estar o filósofo antigo para quem as paixões têm de ser extirpadas e a vida reduzida à essencialidade. Mas, por ora, não podemos substituir personagens, pois era a presença dos físicos no OE que queríamos assinalar ao longo destas linhas. A profícua relação entre filosofia e medicina da alma terá de ficar para uma outra reflexão.

\footnotetext{
${ }^{48}$ OE, Livro IV, cap. XX, p. 163.

${ }^{49}$ Lembre-se que são de uma beleza extrema os ex-votos a St. António por doença.Vd. Henrique Pinto Rema, Santo António de Lisboa. Ex-Votos, Lisboa: Quetzal Editores, 2003.

${ }^{50}$ S. Bernardo, In Cantica, op. cit., Sermo LXVI, p. 826: "Verumtamen si de regula medicorum hoc profers nobis, non reprehendimus curam carnis, quam nemo unquam odio habuit, si tamen non nímia fuerit; si de disciplina abstinentium, id est spiritualium medicorum schola, etiam virtutem approbamus, qua carnem domas, frenas libidinem."

${ }^{51}$ OE, Livro IV, cap. III, p. 97.
} 


\section{Referências Bibliográficas}

\section{Fontes impressas}

BERNARDO (São) - In Cantica, O. C.. Ed. dos monges cistercienses de Espanha. Madrid: BAC, 1987, vol. V.

Orto do Esposo. Edição crítica de Bertil Maler. Rio de Janeiro: Ministério da Educação e Cultura, 1956.

SÉNECA, Cartas a Lucílio. Trad. de Segurado e Campos. Lisboa: Fundação Calouste Gulbenkian, 2009.

\section{Estudos}

FIALON, Charles-Henri - "Histoire des mots «pharmacien et «apothicaire»". In Bulletin de la Société d'histoire de la pharmacie. eISSN - 1775-3864, vol. 8 (1920), p. 262-269.

FITZGERALD, Allan D. et alii (eds.) - Augustine Through the Ages: An Encyclopedia. USA: Eerdmans Publishing Co, 1999. ISBN: 0-8028-3843-X

GUITARD, Eugène-Humbert - "Le physicien, et ce qu'en a dit vers 1200 le moine Guiot de Provins: contribution à l'histoire des mœurs et du langage". In Revue d'histoire de la pharmacie. eISSN - 1775-3864. t. 48, (1960), p. 311-321.

LECLERCQ, Jean - L'amour des Lettres et le Désir de Dieu. 4.ed. Paris: Cerf, 2008. ISBN:978-2-204 08847-3

LERNOULD, Alain - “Le plaisir dans le néoplatonisme”. In Laurence BOULÈGUE e Carlos LEVY (éds.) - Hédonismes. Penser et dire le plaisir dans l'Antiquité et à la 
Renaissance. Villeneuve d'Ascq: Septentrion Presses Universitaires, 2007. ISBN: 9782-85939-919-1, p. 119-137.

LEVEN, Karl-Heinz (ed.) - Antike Medizin. Ein Lexicon. München: Verlag C.H. Beck, 2005. ISBN: 3406528910

MADUREIRA, Margarida - "Sangue Redentor: o Orto do Esposo, a Queste del Saint Graal e a tradição exemplar medieval". In NEVES, Leonor Curado et alii (eds.) Matéria da Bretanha em Portugal. Lisboa: Colibri, 2002. ISBN: 972-772-331-4, p. 241249.

PRIORESCHI, Plinio - A History of Medicine: Medieval Medicine. Omaha: Horatius Press, 2003, vol. V. ISBN: 1-888456-5-1

REMA, Henrique Pinto - Santo António de Lisba. Ex-Votos. Lisboa: Quetzal Editores, 2003. ISBN. 972-564-572-3

SOUSA, Germano de - História da Medicina portuguesa durante a Expansão. Lisboa: Temas e Debates, 2013. ISBN. 978-989-644-219-4

THORNDIKE, Lynn - A history of magic and experimental science. New York: Columbia University Press, 1953-1959, 8 vols. ISBN. 0-231-08794-2

VOELKE, André-Jean - La philosophie comme thérapie de l'âme. Paris: Cerf, 1993. ISBN. 2-8271-0632-9 


\section{COMO CITAR ESTE ARTIGO}

\section{Referência electrónica:}

Henriques, Marisa das Neves - "Os físicos e a medicina da alma no Orto do Esposo". Medievalista [Em linha]. №15, (Janeiro - Junho 2014). [Consultado dd.mm.aaaa].

Disponível em

http://www2.fcsh.unl.pt/iem/medievalista/MEDIEVALISTA15/henriques1504.html.

ISSN 1646-740X.

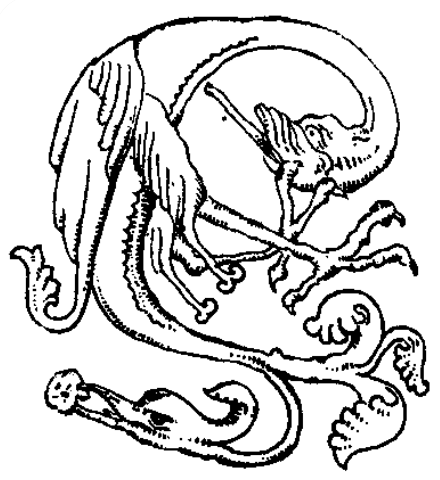

